\title{
DETERMINATION OF 10-GINGEROL IN INDIAN GINGER BY VALIDATED HPTLC METHOD OF SAMPLES COLLECTED ACROSS SUBCONTINENT OF INDIA
}

\author{
KAMRAN ASHRAF ${ }^{1,2,3}$, SYED ADNAN ALI SHAH ${ }^{1,2}$, MOHD MUJEEB ${ }^{3 *}$ \\ 1Faculty of Pharmacy, Universiti Teknologi MARA, Puncak Alam Campus, Bandar Puncak Alam, Selangor Darul Ehsan, Malaysia, ${ }^{2}$ Atta-ur- \\ Rahman Institute for Natural Products Discovery (AuRIns), Universiti Teknologi MARA, Puncak Alam Campus, Bandar Puncak Alam, Selangor \\ Darul Ehsan, Malaysia, ${ }^{3}$ Bioactive Natural Product Laboratory, Faculty of Pharmacy, Jamia Hamdard University, New Delhi 11062 India \\ Email: pharmaresearch9@gmail.com
}

Received: 30 Aug 2016 Revised and Accepted: 15 Oct 2016

\section{ABSTRACT}

Objective: A simple, sensitive, precise, and accurate stability indicating HPTLC (high-performance thin-layer chromatography) method for analysis of 10-gingerol in ginger has been developed and validated as per ICH guidelines.

Methods: The separation was achieved on TLC (thin layer chromatography) aluminum plates pre-coated with silica gel $60 \mathrm{~F}_{254}$ using n-hexane: ethyl acetate 55:45 (\%,v/v) as a mobile phase. Densitometric analysis was performed at $569 \mathrm{~nm}$.

Results: This system was found to have a compact spot of 10 -gingerol at $R_{\mathrm{F}}$ value of $0.57 \pm 0.03$. For the proposed procedure, linearity $\left(r^{2}=0.998 \pm 0.02\right)$, limit of detection (18ng/spot), limit of quantification ( $42 \mathrm{ng} / \mathrm{spot}$ ), recovery (ranging from $98.35 \%-100.68 \%$ ), were found to be satisfactory.

Conclusion: Statistical analysis reveals that the content of 10-gingerol in different geographical region varied significantly. The highest and lowest concentration of 10-gingerol in ginger was found to be present in a sample of Patna, Lucknow and Surat respectively which inferred that the variety of ginger found in Patna, Lucknow are much superior to other regions of India.

Keywords: Ginger, 10-gingerol, HPTLC, Validation

(C) 2016 The Authors. Published by Innovare Academic Sciences Pvt Ltd. This is an open access article under the CC BY license (http://creativecommons.org/licenses/by/4. 0/) DOI: http://dx.doi.org/10.22159/ijpps.2016v8i12.14953

\section{INTRODUCTION}

Ginger (Zingiber officinale Roscoe) Fam. Zingiberaceae is a valued medicinal crop, and it has been used as a spice for over $2000 \mathrm{y}$ [1] This plant is cultivated in many tropical and subtropical countries including China, India, Nigeria, Australia, Jamaica, and Haiti. Among which, China and India are the world's leading producers of ginger [2]. Different cultivars of ginger are growing in different areas in India which were named after the localities from where they are cultivated or collected. Globally gingerols are gaining importance as a budding source of new drug(s) to combat a variety of ailments viz. antitumor, antioxidant, anti-inflammatory, antiapoptotic, cytotoxic, anti-proliferative and anti-platelet activities [3-6].

Ginger contains a number of different pungent and biologically active compounds mainly 6-gingerol, 10-gingerol, 8 gingerols, 6-shogaol, zingerone and paradol [7]. The carbon chain length has also played a significant role in making 10-gingerol (fig. 1) as the most potent antioxidant and anti-inflammatory properties among all the gingerols [8]. This component has also been reported to possess antimicrobial and antifungal properties as well as several pharmaceutical properties [9].

Because of the widespread use of ginger as a spice, dietary supplements, tea, cream, household remedy, as well as an ingredient of various herbal formulations, it is important to know the variety of ginger which contributes the highest yield. Several analytical techniques have been reported for the analysis of gingerols in ginger like high-performance liquid chromatography (HPLC) methods [10, 11], GC/MS (Gaschromatographic-mass-spectrometric) methods [12]. UPLC-MS/MS (Ultra high-performance liquid chromatography and mass spectroscopy) method has also been developed for the analysis of gingerols [13].

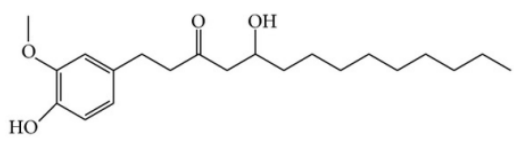

Fig. 1: Chemical structure of 10-gingerol
The literature showed that researcher only evaluated the content of gingerols in different formulations of ginger, but very few or no study has ever been reported to develop a method for quantification of 10-gingerol in different cultivars of ginger collected across subcontinent of India. Keeping in view of their biological importance and its diversity in nature, a sensitive, rapid HPTLC method was developed and validated for the estimation of 10-gingerol in different accessions of ginger. Therefore the objective of this investigation was, to develop a simple, economical, selective, precise, and sensitive HPTLC technique for analysis of 10-gingerol in its methanolic extract of different cultivars of Indian gingers.

\section{MATERIALS AND METHODS}

Chemicals, standards, and samples

Samples of $Z$. officinale were collected from different geographical regions of India (table 5). The plant specimens (GP1, GL2, GDD3, GE4, GB5, GN6, GT7, GDL8, GC9, GB10, GG11 and GS12) were identified by taxonomist Professor M. P. Sharma, Department of Botany, Faculty of Science, Jamia Hamdard, New Delhi. The analytical standard of 10gingerol (purity $>98 \%$ ) was obtained from Ms. chroma dex, anna.

\section{Sample preparation}

Weighed the accurate amount of $5 \mathrm{~g}$ of the dried whole rhizome of $Z$. officinale and then refluxed it for $1 \mathrm{~h}$ with $100 \mathrm{ml}$ methanol on a water bath and filtered through Whatman filter paper (No. 42). The marc left out was refluxed again for three times with $50 \mathrm{ml}$ of methanol for $1 \mathrm{~h}$ and filtered. The filtrates were combined and concentrated to $25 \mathrm{ml}$ in a rotary vacuum evaporator, and the resulting solution was used as a test solution [14].

\section{TLC instrumentation and conditions}

The HPTLC (CAMAG, Switzerland) system, made up of a Linomat IV sample applicator fitted with a 190microliter syringe, a CAMAG twintrough plate development chamber, CAMAG TLC Scanner 3, and Wincats integration software was used. Aluminum backed plates coated with $0.2 \mathrm{~mm}$ layers of silica gel 60 F254 (E. Merck, Germany), 
prewashed with methanol, were used. A constant application rate 150 $\mathrm{nL} / \mathrm{s}$ was employed. The composition of TLC was optimized using different solvents of varying polarity. A good resolution was achieved using n-hexane: ethyl acetate 55:45 (\% v/v) a mobile phase. The plate was visualized with the use of anisaldehyde sulphuric acid reagent. The plate was immersed in the reagent for $1 \mathrm{sec}$ then heated at $105^{\circ} \mathrm{C}$ for $10 \mathrm{~min}$ and then scanned at $569 \mathrm{~nm}$, using a Camag TLC scanner in absorbance mode and the deuterium lamp. The slit dimensions were $4.00 \times 0.45 \mathrm{~mm}$ and the scanning speed was $20 \mathrm{~mm} / \mathrm{s}$.

\section{Preparation of standard solution}

Accurately weighed $1 \mathrm{mg}$ of 10 gingerols and dissolved in $1 \mathrm{ml}$ of methanol. $1 \mathrm{ml}$ of this solution was diluted with methanol to $20 \mathrm{ml}$, which gives $50 \mu \mathrm{g} / \mathrm{ml}$ equivalent of a standard stock solution of 10gingerol. Dilution was made in the different range from the stock and was spotted on TLC plate in six $(n=6)$ to obtain final concentration 50$500 \mathrm{ng} / \mathrm{spot}$ and the concentration was plotted against the area.

\section{Method validation}

The developed method is validated as per the ICH guidelines [15]. Method validation is carried out to confirm that the analytical method employed for this specific analysis is suitable for its intended use. Results from method validation can be used to check its quality, reliability, and consistency. The method was validated by determining linearity, precision, accuracy, limits of detection (LOD), limits of quantification (LOQ), and recovery.

\section{Precision and accuracy}

The intra-day precision and accuracy of the assays were evaluated by performing replicate analyses $(n=6)$ of $Q C$ samples $(100,200$, 300 and $400 \mathrm{ng} / \mathrm{spot}$ ). The inter-day precision and accuracy of the assay were determined by repeating the intra-day assay on three different days. Precision was expressed as the percentage coefficient variation $(\mathrm{CV}, \%)$ of measured concentrations for each calibration level, whereas accuracy was expressed as percent recovery.

\section{Sensitivity and linearity}

In order to estimate detection (LOD) and quantification (LOQ) limits, we spotted blank methanol $(n=6)$ following the same method as explained under the section of chromatographic conditions and the standard deviation $(\sigma)$ of the magnitude of analytical response was determined. The LOD was expressed as (LOD $=3.3 \sigma /$ slope of 10 gingerol calibration curve), whereas LOQ was expressed as (LOQ = $10 \sigma /$ slope of 10 -gingerol calibration curve).

\section{RESULTS AND DISCUSSION}

\section{Selection and optimization of mobile phase}

For the selection of optimum mobile phase at first hexane: ethyl acetate of varying ratios were investigated. The mobile phase hexane: ethyl acetate $(55: 45 \mathrm{v} / \mathrm{v})$ gave a sharp and well-defined peak at $R_{F}$ value of $0.57 \pm 0.03$ for 10 gingerols (fig. 2). Well-defined spots were obtained when the chamber was saturated with the mobile phase for $15 \mathrm{~min}$ at room temperature. For determination of the linearity curves of area vs concentration, different amounts of a stock solution of 10-gingerol was applied on the HPTLC plate and analyzed. HPTLC peak of Lucknow sample was shown in fig. 3.

\section{Calibration curve}

Calibration was linear in the concentration range 50-500 ng. The linear regression equation was $Y=11.62 x+1640.38$, while the correlation coefficients (r2) was $0.9987 \pm 0.02$, with high reproducibility and accuracy (table 1$)$.

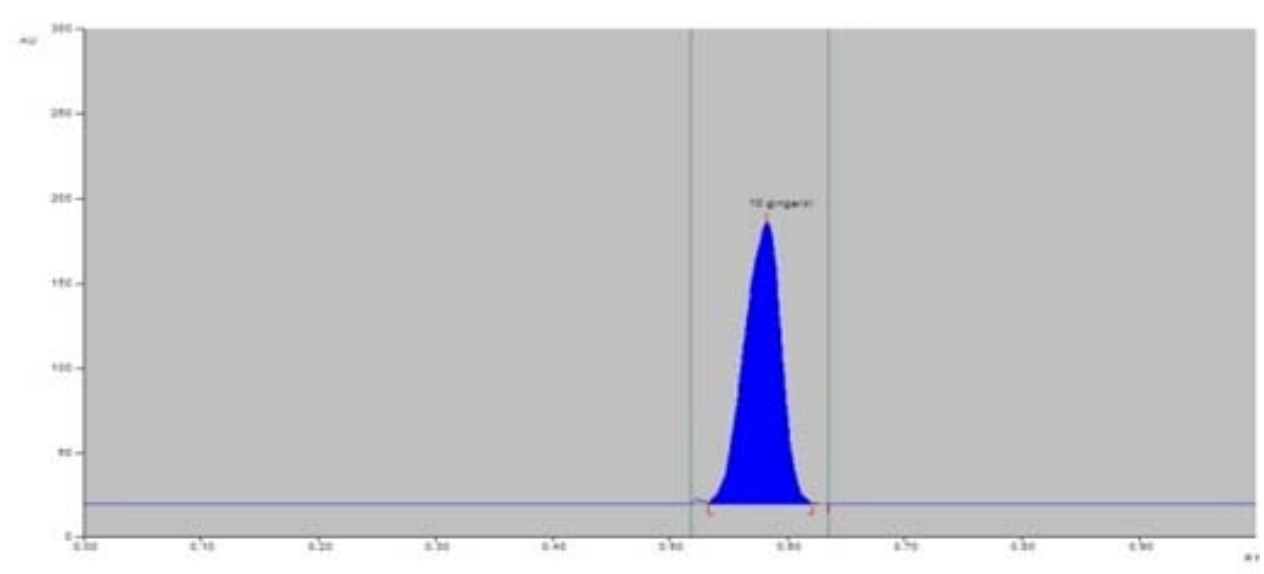

Fig. 2: HPTLC densitogram of standard 10-gingerol at $R_{F} 0.57 \pm 0.03$

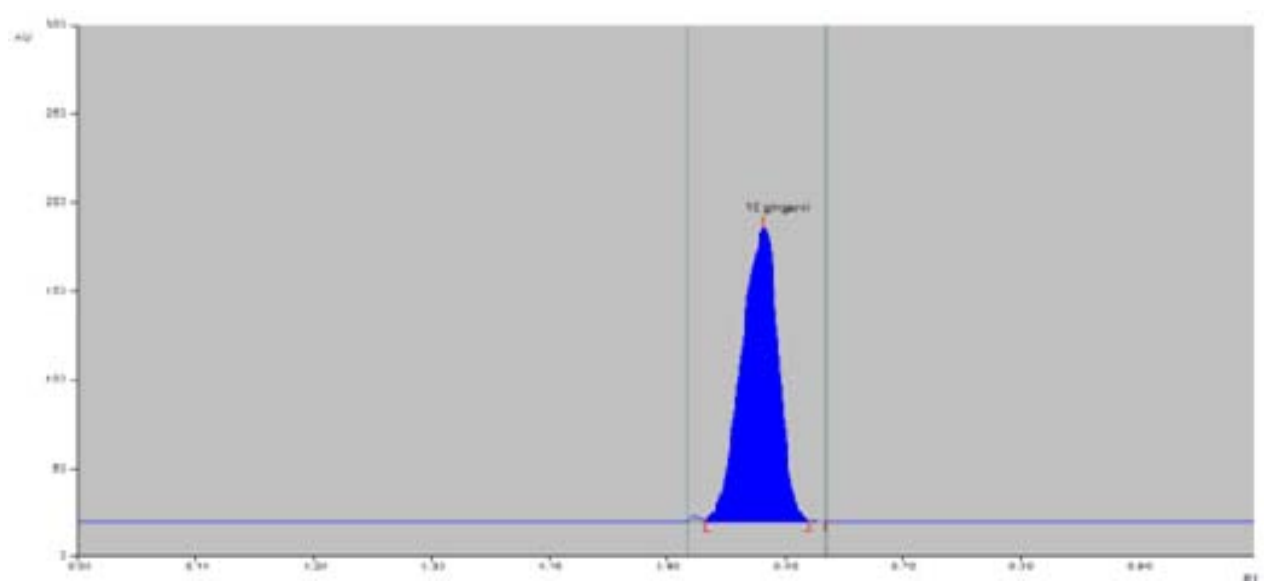

Fig. 3: HPTLC densitogram of Lucknow sample of 10-gingerol at $R_{F} 0.57 \pm 0.06$ 
Table 1: Linear regression data for the calibration plot $(n=6)$

\begin{tabular}{lc}
\hline Parameters & Observation \\
\hline Linearity range (ng/spot) & $50-500$ \\
Correlation coefficient (r2) & $0.998 \pm 0.02$ \\
Regression equation & Y $=11.62 \times+1640.38$ \\
Slope \pm SD & $11.62 \pm 0.312$ \\
Intercept b \pm SD & $1640.38 \pm 0.997$ \\
LOD (ng/spot) (Limit of detection) & 18 \\
LOQ (ng/spot) (Limit of quantification) & 48 \\
\hline
\end{tabular}

The detection limit of 10-gingerol was determined by plotting a series of concentrations on the plate and scanning at 569 nm. The lowest amount of 10 -gingerol which could be detected (LOD) was $18 \mathrm{ng} / \mathrm{spot}$. The lowest amount of 10-gingerol which could be quantified (LOQ), was found to be 48ng/spot (table 1).

\section{Validation of method}

\section{Recovery studies}

The proposed method, when used for estimation of 10 -gingerol after spiking with 50,100 and $150 \%$ of the additional drug, afforded recovery ranging from $98.35 \%-100.68 \%$ for 10 -gingerol was obtained as listed in table 2 . The \%RSD of recovery of 10 -gingerol was ranged from $0.14 \%-0.34 \%$ (table 2 ).

\section{Precision and accuracy}

The intra-and inter-day precision, as the coefficient of variation (CV, $\%$ ) and accuracy of the assay determined at 10-gingerol concentration of $100,200,300$, and $400 \mathrm{ng} / \mathrm{spot}$ have been summarized in (table 3). The intra-day precision $(n=6)$ was $\leq 1.62 \%$. The inter-day precision over three different days was $\leq 1.98 \%$. The intra-day and inter-day accuracy were in the range of $98.60 \%-100.50 \%$ and $98.37 \%-99.73 \%$, respectively. The repeatability of the method was studied by assaying six samples of 10-gingerol at same concentration under the same experimental conditions. The values were within the acceptable range, and so we concluded that the method was accurate, reliable and reproducible (table 3).

\section{Robustness of the method}

The standard deviation of peak areas was calculated for each parameter and \%RSD was found to be in the acceptable range. The $\%$ RSD (0.85-1.87) obtained after introducing small deliberate changes in the developed HPTLC method indicated the robustness of the method (table 4).

Table 2: Recovery study of 10-gingerol

\begin{tabular}{lll}
\hline Excess drug added to the analyte (\%) & Theoretical content(ng) & \%Recovery \\
\hline 0 & 100 & 98.98 \\
50 & 150 & 9.34 \\
100 & 200 & 023 \\
150 & 250 & 9.56 \\
\hline
\end{tabular}

Table 3: Intra and inter day precession of HPTLC method $(n=6)$ for 10-gingerol

\begin{tabular}{|c|c|c|c|}
\hline Nominal concentration/ng per spot & Concentration found ${ }^{\text {/ng per spot }}$ & Precision $^{b}(\mathrm{CV}, \%)$ & \%Accuracyc \\
\hline \multicolumn{4}{|l|}{ Intra-day } \\
\hline 100 & 98.65 & 1.62 & 98.65 \\
\hline 200 & 198.65 & 1.32 & 99.32 \\
\hline 300 & 296.87 & 1.12 & 98.95 \\
\hline 400 & 406.10 & 1.32 & 101.50 \\
\hline \multicolumn{4}{|l|}{ Inter-day } \\
\hline 100 & 99.73 & 1.98 & 99.73 \\
\hline 200 & 197.56 & 1.04 & 98.78 \\
\hline 300 & 295.12 & 1.23 & 98.37 \\
\hline 400 & 398.34 & 1.98 & 99.58 \\
\hline
\end{tabular}

aMean of six determinations $(n=6)$, bPrecision as coefficient of variation $(\mathrm{CV}, \%)=$ standard deviation divided by concentration found $\mathrm{x} 100$, c\% Accuracy = concentration found/nominal concentration $\mathrm{x} 100$

Table 4: Robustness of the method $(n=6)$ for 10-gingerol

\begin{tabular}{lll}
\hline 10-gingerol & Mobile phase composition & \\
\hline Amount (ng per spot) & n-hexane: ethyl acetate 50:50 (\%,v/v) \% RSD & n-hexane: ethyl acetate 55:45 (\%, v/v) \% RSD \\
200 & 1.54 & 0.89 \\
400 & 0.85 & 1.87 \\
\hline
\end{tabular}

\section{LOD and LOQ}

The calibration curve in this study was plotted between the amount of analyte versus average response (peak area) and the regression equation was obtained $Y=11.62 x+1640.38$ over the concentration range 50-500 ng/spot with respect to the peak area with a regression coefficient of 0.998 . Limit of detection (LOD) and limit of quantification (LOQ) was calculated by the method as described in validation section and was found to be 18 and 42 ng respectively, which indicates the ample sensitivity of the method. Different samples of gingerols in ginger were observed and calculated (table 5). The proposed method is simple, precise, specific, accurate, less time consuming and cost effective. Statistical analysis proved that the method is evitable for the analysis of 10 -gingerol. HPTLC method 
is helpful in determining the qualitative and quantitative analysis of herbal and dietary supplements, nutraceuticals, and various types of medicines. This method can also be used in quality control and in purity checks, in the detection and identification of pharmaceutical raw materials, drugs and their metabolites in biological media. HPTLC method is also a very influential tool for identification of the presence of adulterants in herbal products based on the distinguishing image produced and much useful for determining the presence and the quantification of both unintended substitutions as well as deliberate adulteration of drugs [16]. Hasan and Saleh [17] reported the different contents of 10 gingerols in the ginger extract, ginger-containing dietary supplements, teas and commercial creams but these data only showed the content of 10 gingerols in three different types of preparations. In this proposed experiment different accessions have been studied and reported that highest and lowest percentage of 10-gingerol was found to be in a sample of Lucknow, Patna (east) and Surat (west) samples respectively. The experimental result shows that the variety of $Z$. officinal of Patna and Lucknow samples are superior to other regions. This experimental result endorsed the Patna and Lucknow variety of ginger are of best quality among all varieties found in India. These results are also confirmatory to finding of Ashraf et al. by UPLC-MS method.

Table 5: Concentration (mg/g) of 10-gingerol in different samples of Z. officinale by HPTLC method

\begin{tabular}{lll}
\hline S. No & Samples & 10-gingerol content(mg/g) \\
\hline 1 & Patna (Bihar) & $0.43 \pm 0.013$ \\
2 & Lucknow (Uttar Pradesh) & $0.43 \pm 0.021$ \\
3 & Dehradun (Utrakhand) & $0.35 \pm 0.011$ \\
4 & Erode (Tamilnadu) & $0.39 \pm 0.121$ \\
5 & Bangalore (Karnataka) & $0.35 \pm 0.012$ \\
6 & Nashik (Maharashtra) & $0.43 \pm 0.014$ \\
7 & Trivandrum (Kerala) & $0.39 \pm 0.105$ \\
8 & Delhi (Delhi) & $0.34 \pm 0.101$ \\
9 & Chandigarh (Punjab) & $0.28 \pm 0.011$ \\
10 & Bhopal (M. P.) & $0.34 \pm 0.021$ \\
11 & Guwahati (Assam) & $0.41 \pm 0.012$ \\
12 & Surat (Gujrat) & $0.21 \pm 0.101$ \\
\hline
\end{tabular}

\section{CONCLUSION}

The HPTLC method for quantitating 10-gingerol is simple, accurate, reproducible and sensitive and is applicable to the analysis of a wide variety of ginger-containing products. In this experimental results showed that highest and lowest percentage of 10-gingerol was found to be in a sample of Lucknow, Patna, and Surat samples respectively. These variations could be due to different environmental and soil conditions of different areas. The method established in this study could be used for the quality control of herbal medicine derive from ginger species. From this experiment, it is concluded that variety of $Z$. officinale of Patna and Lucknow are superior to other regions and these could be used for large-scale production. This research could provide important input for making strategies for cultivation of this plant.

\section{ACKNOWLEDGMENT}

Syed Adnan Ali Shah would like to acknowledge the Ministry of Higher Education (MOHE) for financial support under the Fundamental Research Grant Scheme (FRGS) with sponsorship reference numbers FRGS/1/2015/SG05/UiTM/02/6. The author would also like to acknowledge Universiti Teknologi MARA for the financial support under the reference number 600-IRMI/FRGS 5/3 (135/2015).

\section{CONFLICT OF INTERESTS}

\section{Declared none}

\section{REFERENCES}

1. Bartley J, Jacobs A. Effects of drying on flavor compounds in Australian-grown ginger (Zingiber officinale). J Sci Food Agric 2000;80:209-15.

2. Blumenthal M, Goldberg A, Brinckmann J. Ginger root. In Herbal medicine: Expanded commission E monographs 2000;159:153-290.

3. Sekiw Y, Kubota K, Kobayashi A. Isolation of novel glucosides related to gingerdiol from ginger and their antioxidative activities. J Agric Food Chem 2000;48:373-77.

4. Shukla Y, Singh M. Cancer preventive properties of ginger: a brief review. Food Chem Toxicol 2007;45:683-90.

5. Wei QY, Ma JPY, Cai J, Yang L, Liu ZL. Cytotoxic and apoptotic activities of diarylheptanoids and gingerol-related compounds from the rhizome of Chinese ginger. J Ethnopharmacol 2005;102:177-84.

6. Young HY, Luo YL, Cheng, HY, Hsieh WC, Liao JC, Peng. Analgesic and anti-inflammatory activities of 6-gingerol. J Ethnopharmacol 2005;96:207-10.
7. Govindarajan VS. Ginger-chemistry, technology and quality evaluation: part 1. CRC Crit Rev Sci Nutr 1982;17:1-96.

8. Dugasani S, Pichikac MR, Nadarajah VD, Balijepalli MK, Tandra S, Korlakunta JN. Comparative antioxidant and antiinflammatory effects of [6]-gingerol, [8]-gingerol, [10]-gingerol and [6]-shogaol. J Ethnopharmacol 2010;127:515-20.

9. Park M, Bae J, Lee D. Antibacterial activity of [10]-gingerol and [12]-gingerol isolated from ginger rhizome against periodontal bacteria. Phytother Res 2008;22:1446-9.

10. Wang WH, Wang ZM, Xu LZ, Yang SL. HPLC determination of 6gingerol in rhizoma Zingiberis recens. Zhongguo Zhongyao Zazhi 2002;27:348-9.

11. Wood AB. Determination of the pungent principles of chillies and ginger by reversed-phase high-performance liquid chromatography with use of a single standard substance. Flavour Fragrance J 1987;2 Suppl 1:1-12.

12. Mahdi HJ, Andayani R, Ishak. Metabolic fingerprinting of three Malaysian Ginger (Zingiber officinale Roscoe) using gas chromatography-mass spectrometry. Am J Appl Sci 2010;7 Suppl 1:17-23.

13. Ashraf K, Mujeeb M, Ahmad A, Ahmad S, Ahmad N, Amir M. Determination of gingerols in ginger by ultra-high performance liquid chromatography-tandem mass spectrometry. Anal Lett 2014;47:2120-8

14. Alam P. Densitometric HPTLC analysis of 8-gingerol in Zingiber officinale extract and ginger-containing dietary supplements, teas and commercial creams. Asian Pac J Trop Biomed 2013;3:634-8.

15. ICH, Q2 (R1), International Conference on Harmonization, Geneva; 2005.

16. Chidambaram V, Niraimathi L, Sudha V, Lavanya R, Vadivel V, Brindha P. Spectrophotometric, HPTLC and GC-MS studies on selected spice extracts. Int J Pharm Pharm Sci 2015;7:184-90.

17. Yusufoglu H, Alqasoumi SI. High-Performance thin layer chromatographic analysis of 10-gingerol in Zingiber officinale extract and ginger-containing dietary supplements, teas and commercial creams. FABAD J Pharm Sci 2008;33:199-204.

\section{How to cite this article}

- Kamran Ashraf, Syed Adnan Ali Shah, Mohd Mujeeb. Determination of 10-gingerol in Indian ginger by validated HPTLC method of samples collected across subcontinent of India. Int J Pharm Pharm Sci 2016;8(12):190-193. 